УДК 621.774

Е.И. Шифрин /д.т.н./, А.Ф. Гринев /к.т.н./
Национальная металлургическая академия

Украины, г. Днепр, Украина

\title{
АНАЛИТИЧЕСКИЙ ОБЗОР СОВРЕМЕННЫХ ТРЕБОВАНИЙ К КАЧЕСТВУ ГОРЯЧЕДЕФОРМИРОВАННЫХ ТРУБ НЕФТЯНОГО СОРТАМЕНТА
}

Ye.I. Shyfrin / Dr. Sci. (Tech.)/, A.F. Hrynov / Cand. Sci. (Tech.)/
National Metallurgical Academy of Ukraine, Dnipro, Ukraine

\section{ANALYTICAL REVIEW OF MODERN REQUIREMENTS FOR HOT FINISHED OIL PIPES QUALITY}

Цель. В связи с разведкой новых месторождений углеводородов, различием залегания продуктивных пластов, поддержанием дебита существующих скважин, перед наукой и практикой постоянно возникает необходимость решения проблем создания новых конструкций скважин, резьбовых соединений труб и муфт, повышения прочностных характеристик металла, ужесточения контроля технологических параметров и др.

Методика. Выполненный анализ ужесточения требований к качеству труб выявил, что изменения этих требований с учетом существующих методов оченки коснулись абсолютно всех составляющих качества трубной продукции, начиная от требований к исходным материалам и заканчивая требованиями к товарному виду продукиии и технологии ее производства. При этом сравнивались требования действующих отечественных, зарубежных, международных стандартов на трубы и спецификаџии ведущих мировых трубопотребляющих компаний.

Научная новизна. Обобщены результаты анализа современных требований к качеству $и$ технологии производства горячедеформированных труб для разведки, добычи и транспортировки нефти и газа. Определены тенденции развития и совершенствования технологий производства труб нефтяного сортамента.

Результаты, практическая значимость. На основании требований спецификаџий ведущих мировых нефтегазодобывающих компаний (SHELL, SHEVRON, EXONN MOBIL, ADCO, SAUDI ARAMCO, LUKOIL, ГАЗПРОМ, РОСНЕФТЬ и др.) проанализированы современные тендениии развития требований к показателям качества трубной продукиии, в частности, к горячедеформированным трубам нефтяного сортамента. Приведены требования к способу производства стали и трубной заготовки, к химическому составу сталей, к механическим свойствам, к качеству поверхности и, к геометрическим размерам, форме и массе труб, к методам неразрушающего контроля и испытаний, к методам приемки и контроля, маркировки, упаковки, транспортировки и хранения, а также к технологии производства труб. С учетом изложенного изготовители трубной продукции будут вынуждены приходить к решительным мерам по замене уже устаревших трубопрокатных агрегатов или их коренной реконструкиии с учетом экономической иелесообразности.

Ключевые слова: горячедеформированные трубы, показатели качества, трубопрокатный агрегат, химический состав, механические свойства, неразрушающий контроль.

DOI: 10.34185/0543-5749.2019-3-4-56-61

Введение. В течение последних двух десятилетий во всех основных трубопотребляющих отраслях (машиностроение, нефтегазодобыча, строительство, ЖКХ и других) наблюдается устойчивая тенденция к росту требований к

качеству труб. Эта тенденция прослеживается во всех без исключения промышленных регионах мира. Особенно ярко она выражена в требованиях нефтегазодобывающей промышленности [1]. Так, практически весь прирост потребления труб

() Шифрин Е.И., Гринев А.Ф., 2019 г. 
нефтяного сортамента (в зависимости от региона - это $7-12 \%$ в год) приходится на трубы с повышенными качественными характеристиками и потребительскими свойствами. Вместе с тем, наблюдается достаточно устойчивое падение спроса на трубы «стандартного» качества.

Объяснение этой тенденции достаточно простое. Во-первых - значительное усложнение условий разведки, добычи и транспортировки углеводородов, а также внедрение новых технологий строительства нефтяных и газовых скважин (горизонтальное и наклонное бурение, внедрение технологии гидроразрыва пластов, шельфовая добыча нефти и газа, подводная транспортировка углеводородов и т.п.). Вовторых - это экономическая составляющая. Использование более дорогих, но более качественных и надежных труб, в конечном счете, приводит к уменьшению металлоемкости скважин и трубопроводов, снижению затрат на ремонты и устранение последствий аварий [2].

Анализ ужесточения требований к качеству труб выявил, что изменения требований коснулись абсолютно всех составляющих качества трубной продукции, начиная от требований к исходным материалам и заканчивая требованиями к товарному виду продукции и технологии их производства.

При этом сравнивались требования действующих отечественных, зарубежных, международных стандартов и спецификаций ведущих мировых трубопотребляющих компаний.

Перспективные требования к качеству трубной продукции (спецификации SHELL, SHEVRON, EXONN MOBIL, ADCO, SAUDI ARAMCO, LUKOIL, ГAЗПРOM, РОСНЕФTЬ и др.).

1. Требования к способу производства стали и трубной заготовки:

- сталь должна быть полностью раскислена алюминием;

- обязательно должно определяться содержание кислорода в ковшевой пробе;

- обязательное проведение внепечного рафинирования стали;

- обязательное проведение вакуумирования;

- обязательное перемешивание стали в кристаллизаторе;

- сталь должна разливаться сериями;

- запрещается разливка «плавка на плавку».

2. Требование к химическому составу сталей:

- массовая доля серы не более 0,008 \%, массо- вая доля фосфора не более $0,115 \%$;

- химический анализ проводится по ковшевой пробе и в продукции;

- массовая доля остаточных химических элементов в стали по анализу ковшевой пробы и продукции не более, \%: $\mathrm{Sn}=0,015$; $\mathrm{Sb}=0,01 ; \mathrm{Bi}=0,005 ; \mathrm{Pb}=0,005 ; \mathrm{As}=0,015$; $\mathrm{B}=0,0005 ; \mathrm{Ca}=0,004$;

- отношение массовых долей $\mathrm{Al} / \mathrm{N}$ в стали не менее 2,0;

- массовая доля водорода по ковшевой пробе не более 2 ppm;

- массовая доля азота - не более $0,008 \%$;

- массовая доля кислорода в стали по ковшевой пробе и в изделии не более $0,0035 \%$;

- разброс массовых долей химических элементов (общее поле) не более, \%: $\mathrm{C}=0,04$; $\mathrm{Mn}=0,03 ; \quad \mathrm{Si}=0,25 ; \quad \mathrm{Ni}=0,1 ; \quad \mathrm{Cu}=0,1 ;$ $\mathrm{V}=0,03 ; \quad \mathrm{Nb}=0,02 ; \quad \mathrm{Al}=0,04 ; \quad \mathrm{Ti}=0,015 ;$ $\mathrm{Mo}=0,05$;

- сталь должна быть выплавлена в электропечи либо в конверторе.

3. Требования к механическим свойствам труб:

- механические свойства при испытаниях на растяжение (см. табл. 1);

- трубы должны иметь высокое сопротивление всестороннему сжатию (усилие сжатия не менее $120-140 \% \sigma_{\mathrm{T}}$ ) - класс труб Higt Collaps [3];

- механические свойства при испытаниях на ударный изгиб приведены в табл. 2.

4. Требования к качеству поверхности $и$ металлу труб:

- на наружной поверхности труб не должно быть отслаивающейся окалины, плен, раковин, ужимов, задиров, закатов, рванин, и других несовершенств поверхности глубиной более $5 \%$ толщины стенки (можно удалять абразивной зачисткой с плавным переходом к прилегающим поверхностям);

- на наружной поверхности допускаются вмятины размером в любом направлении не более $25 \%$ от величины наружного диаметра и глубиной не более 2 мм (удаление вмятин не допускается);

- на поверхности фаски труб не допускаются расслоения (удаление несовершенств поверхности на фаске, за исключением заусенцев, не допускается);

- не допускаются несовершенства поверхности с острым дном глубиной более 0,5 мм;

- трубы должны выдерживать испытательное 
гидростатическое давление в течение 10 сек. равное $96 \% \sigma_{\mathrm{T}}$;
- остаточная намагниченность металла труб должна быть не более 20 Гс (2,0 мТл).

Таблица 1. Механические свойства при испытаниях на растяжение

\begin{tabular}{|c|c|c|}
\hline $\begin{array}{c}\text { Группа } \\
\text { прочности* }\end{array}$ & $\begin{array}{c}\text { Отношение } \sigma_{\mathrm{T}} / \sigma_{\mathrm{B}}, \\
\text { не более }\end{array}$ & $\begin{array}{c}\text { Относительное удлинение } \delta(\%), \\
\text { не менее }\end{array}$ \\
\hline L290Q / X42Q & 0,85 & \multirow{2}{*}{20} \\
\hline L320Q / X46Q & 0,85 & \\
\hline L360Q / X52Q & 0,85 & \\
\hline L415Q / X60Q & 0,88 & \\
\hline L450Q / X65Q & 0,90 & \\
\hline L485Q / X70Q & 0,92 & \\
\hline
\end{tabular}

*Группы прочности указаны по стандартам ASTM и API.

Таблица 2. Механические свойства при испытаниях на ударный изгиб

\begin{tabular}{|c|c|c|c|}
\hline $\begin{array}{c}\text { Наименование } \\
\text { показателя }\end{array}$ & $\begin{array}{c}\text { Значение показателя } \\
\text { для отдельного образца } \\
\text { 10x10 мм, не менее }\end{array}$ & $\begin{array}{c}\text { Среднее значение } \\
\text { для комплекта из трех } \\
\text { образцов, не менее } \\
\end{array}$ & $\begin{array}{l}\text { Температура испытаний, } \\
\text { C / толщина стенки трубы }\end{array}$ \\
\hline $\begin{array}{l}\text { Работа удара } K \mathrm{v}, \\
\text { Дж }\end{array}$ & 60 & - & \multirow{2}{*}{$\begin{array}{c}\text { - 10/до } 20 \text { мм } \\
\text { включительно; } \\
\text { - 20/ до } 30 \text { мм включительно; } \\
\text { - } 30 / \text { свыше } 30 \text { мм }\end{array}$} \\
\hline $\begin{array}{l}\text { Вязкая } \\
\text { составляющая, \% }\end{array}$ & 75 & 85 & \\
\hline
\end{tabular}

Для поперечных образцов с концентратором вида V полного размера.

\section{5. Требования к геометрическим размерам,} форме и массе труб:

- предельные отклонения наружного диаметра, кроме концов труб длиной не менее 100 мм от торца:

- для труб с наружным диаметром до 310 мм включительно - $\pm 0,50 \%$, но не более $\pm 1,25$ мм;

- для труб с наружным диаметром свыше 310 мм - не более \pm 1,5 мм.

- предельные отклонения внутреннего диаметра, кроме концов труб длиной не менее 100 мм от торца:

- для труб с наружным диаметром до 310 мм включительно - не более $+1,6 /-0,4$ MM;

- для труб с наружным диаметром свыше 310 мм - не более + 2,4/- 0,8 мм.

- предельные отклонения толщины стенки труб:

- для труб с толщиной стенки до 15 мм включительно - не более $+12,5 /-10 \%$;

- для труб с толщиной стенки свыше 15 мм - не более $\pm 10 \%$.

- отклонения от общей прямолинейности - не более 0,15 \% длины трубы, на любом участке трубы длиной 1 м - не более 1,4 мм;

- отклонения массы отдельной трубы, не более $+5,0 /-3,5 \%$;
- разница значений наружных и внутренних диаметров на концах труб одной группы прочности, размера по одной позиции заказа не должна превышать 1,6 мм (данному требованию должны удовлетворять не менее 75 \% труб по одной позиции заказа).

6. Требования к неразрушающему контролю:

- каждая труба по всей длине должна подвергаться ультразвуковому и электромагнитному контролю (метод рассеяния магнитного потока или вихретоковый метод);

- требования к ультразвуковому контролю:

- уровень приемки U2 по ISO 10893-10 для выявления продольных, поперечных и наклонных $\left(22^{\circ}, 45^{\circ}\right.$ и $\left.67^{\circ}\right)$ несовершенств наружной и внутренней поверхности труб;

- уровень приемки U2 по ISO 10893-8 для выявления расслоений;

- контроль толщины стенки трубы с охватом $100 \%$ всей поверхности тела трубы.

- проверка на устойчивость должна производиться после каждой перенастройки на трубы другой группы прочности и размера при условиях:

- испытания проводятся в динамическом режиме;

- при использовании шкалы в процен- 
тах, сигналы устанавливаются на $80 \%$ $\pm 5,0 \%$ высоты экрана;

- угол ввода ультразвуковых колебаний относительно наружной поверхности трубы $45^{\circ} \pm 3,0^{\circ}$.

- требования к электромагнитному контролю:

- уровень приемки F2 по ISO 10893-3 для метода рассеяния магнитного потока;

- уровень приемки E2 по ISO 10893-2 для вихретокового метода.

7. Требования к методам приемки иконтроля, маркировки, упаковки, транспортировки и хранения:

- контроль концов труб осуществляется с помощью калибров-пробок;

- разность между номинальным внутренним диаметром труб и калибром-пробки - не более $2 \%$ номинального внутреннего диаметра, но не более 3,2 мм для труб с толщиной стенки до 20 мм включительно и 4,0 мм для труб с толщиной стенки более 20 мм;

- калибр-пробка должен свободно проходить коней трубы не менее 100 мм;

- $\quad$ требования к маркировке (для гладких труб):

- на фаске труб малым усилием должен быть нанесен клеймением порядковый номер трубы в партии;

- на противоположный конец трубы должна быть нанесена маркировка краской (высота шрифта не менее 30 мм);

- маркировка защищается лаком, обеспечивающим сохранность маркировки на воздухе в течение не менее 1 года;

- каждый пакет труб должен снабжаться двумя строповочными текстильными хомутами

- трубы должны поставляться с консервационным покрытием для защиты от коррозии при - транспортировании и хранении в течение не менее 12 месяцев с даты отгрузки.

Одним из перспективных методов за щиты металла труб от коррозии является термодиффузионное нанесение на наружную и внутреннюю поверхности слоя цинка. Результаты промысловых испытаний насосно-компрессорных труб с таким покрытием показали, что сопротивление коррозии у них возрастает в десятки раз [4].

\section{8. Требования к технологии:}

- требование к прослеживаемости каждой единичной трубы, партии и плавки на протяжении всего цикла производства. Данные требования регламентируются стандартами ISO 9001, API Q1, а также национальными стандартами и нормами различных стран. Принимая во внимание общемировую практику осуществления закупок, в том числе труб, на тендерной основе, выполнение требования к прослеживаемости, наряду с удовлетворением условий по качеству, а также наличие подтверждающих сертификатов является обязательным условием участия продавцов в тендерах [5].

Исходя из данных требований, все большее значение приобретает объективный контроль в непрерывном режиме технологических параметров и качественных характеристик труб на всех производства. В результате, даже на достаточно устаревшем оборудовании, становится реальным без проведения коренной реконструкции технологического оборудования существенно повысить выход годного при производстве труб с ужесточенными качественными характеристиками [6].

Понимая, что оставаться в сегменте производства труб т.н. «стандартного» качества можно будет достаточно ограниченное время, ведущие трубные компании (Tenaris, Valurec, Dalmine, Nippon Steel, TMK, Baosteel и другие) выбрали путь строительства новых трубопрокатных агрегатов, позволяющих производить трубы с указанными показателями качества и вывода из эксплуатации устаревшего технологического оборудования. Так, за период 2000 - 2015 годы в различных странах было введено в эксплуатацию более 30 современных трубопрокатных агрегатов, в том числе 24 агрегата со станами PQF и FQM с трехвалковыми клетями и подверглись коренной реконструкции с заменой отдельных станов более 15 трубопрокатных агрегата. Часть устаревших трубопрокатных агрегатов было выведено из эксплуатации. Это, в основном, ТПА с пилигримовыми станами и автомат - станами.

Кроме того, практически во всех странах горячедеформированные трубы прекратили изготавливать из металла, выплавленного в мартеновских печах [7].

Выводы. 1. В сравнении с трубами «стандартного» качества, трубы с ужесточенными показателями демонстрируют устойчивый рост спроса на мировом рынке и имеют существенно более высокую рентабельность.

2. Трубные компании, которые своевременно приняли стратегию развития производства труб с ужесточенными показателями качества в настоящее время демонстрируют прочное финансовое состояние и занимают лидирующие позиции в мировой трубной промышленности. 
3. С учетом вышеизложенного и тенденции объема производства горячедеформированных труб с ужесточенными качественными характеристиками маркетинговые структуры потребителей должны сопоставлять рост потребительской стоимости на эту продукцию и выгоду от ее применения с учетом затрат на эксплуатацию.

\section{Библиографический список}

1. Козловский А.И., Шифрин Е.И. Трубная промышленность Украины. Краткий анализ рынка трубной продукции. Металургійна наука підприємствам Придніпров'я : збірник наукових праць. Дніпропетровськ, Системні технології, 2004. С. 89-94.

2. Козловский А.И., Шифрин Е.И., Гуляев Ю.Г. Некоторые проблемы повышения эффективности производства труб. Теория и проактика металлургии. 2004. № 5. С. 38-41.

3. S. Abraham, J. Raines, R. Bodnar. Development of an Inclusion Characterization Methodology for Improving Steel Product Cleanliness. Iron and Steel Technology. 2014. February. P. 219-234.

4. Опыт промышленной эксплуатации диффузионнооцикованных насоснокомпрессорных труб на глубоких нефтяных скважинах / А.И. Козловский и др. Коррозия: материалы и защита. 2005. № 10. С. 6-10.

5. Совершенствование методов и средств для обеспечения индетификации и прослеживаемости продукции в системе управления качеством товаропроизводящих цехов / В.П. Сокуренко и др. Трубокон-2001 : материалы 2-й МНПК по проблемам совершенствования производства и эксплуатации трубной продукции. Днепропетровск, 2001. С. 59-64.

6. The modern trends of development of the pipe and tube industry/ Yu. Gulyayev et. al. Metalurgija. 2010. № 3(49). P. 187-190.

7. Шифрин Е.И., Клачков А.А. Текущее состояние российской трубной отрасли. Развитие ПАО «ТМК»- ведущего производителя труб. Труды Х Конгресса прокатчиков (том II). М.: Ваш формат, 2015. С. 26-35.

\section{References}

1. Kozlovskii, A.I., \& Shifrin, E.I. (2004). Trubnaia promyshlennost Ukrainy. Kratkii analiz rynka trubnoi produktcii. Metalurhiina nauka pidpryiemstvam Prydniprovia. Zbirnyk naukovykh prats. (pp. 89-94). Dnipropetrovsk: Systemni tekhnolohii.

2. Kozlovskii, A.I., Shifrin, E.I., \& Guliaev, Yu.G. (2004). Nekotorye problemy povysheniia effektivnosti proizvodstva trub. Teoriia $i$ proaktika metallurgii, (5), 38-41.

3. Abraham, S., Raines, J., \& Bodnar, R. (2014). Development of an Inclusion Characterization Methodology for Improving Steel Product Cleanliness. Iron and Steel Technology, February, 219-234.

4. Kozlovskii, A.I., Pinchuk, S.I., Shifrin, E.I., et. al. (2005). Opyt promyshlennoi ekspluatatcii diffuzionnootcikovannykh nasosnokompressornykh trub na glubokikh neftianykh skvazhinakh. Korroziia: materialy i zashchita, (10), 6-10.

5. Sokurenko, V.P., Shifrin, E.I., Fridman, V.M., et. al.(2001). Sovershenstvovanie metodov i sredstv dlia obespecheniia indetifikatcii i proslezhivaemosti produktcii $\mathrm{v}$ sisteme upravleniia kachestvom tovaroproizvodiashchikh tcekhov. Trubokon-2001. Materialy 2-i MNPK po problemam sovershenstvovaniia proizvodstva $i$ ekspluatatcii trubnoi produktcii. Dnepropetrovsk.

6. Gulyayev, Yu., Mamuzsc, I., Shifrin, Ye. et. al. (2010). The modern trends of development of the pipe and tube industry. Metalurgija, 3(49), 187190.

7. Shifrin, E.I., \& Klachkov A.A. (2015). Tekushchee sostoianie rossiiskoi trubnoi otrasli. Razvitie PAO "TMK" - vedushchego proizvoditelia trub. Trudy Kh Kongressa prokatchikov, 2, Moskva: Vash format.

Мета. У зв'язку з розвідкою нових родовищ вуглеводнів, відмінністю залягання продуктивних пластів, підтриманням дебіту існуючих свердловин, перед наукою і практикою постійно виникає необхідність вирімення проблем створення нових конструкиій свердловин, різьбових з'єднань труб і муфт, підвищення міцності металу, посилення контролю за технологічними параметрами та ін.

Методика. Виконаний аналіз посилення вимог до якості труб виявив, що зміна иих вимог з урахуванням існуючих методів оцінки торкнулась абсолютно всіх складових якості трубної продукиії, починаючи від вимог до вихідних матеріалів $i$ закінчуючи вимогами до товарного вигляду продукції та технології іï виробництва. При цьому порівнювалися вимоги діючих вітчизняних, зарубіжних, міжнародних стандартів на труби і специфікації провідних світових компаній, що використовують труби.

Наукова новизна. Узагальнено результати аналізу сучасних вимог до якості і технологіі виробничтва гарячедеформованих труб для розвідки, видобутку і транспортування нафти 
та газу. Визначено тендениії розвитку та вдосконалення технологій виробництва труб нафтового сортаменту.

Практична значущість. На підставі вимог спеичфікацій провідних світових нафтогазовидобувних компаній (SHELL, SHEVRON, EXONN MOBIL, ADCO, SAUDI ARAMCO, LUKOIL, ГАЗПРОМ, РОСНЕФТЬ $і$ ін.) проаналізовано сучасні тендениії розвитку вимог до показників якості трубної продукиії, зокрема, до гарячодеформованих труб нафтового сортаменту. Наведено вимоги до способу виробництва сталі і трубної заготовки, до хімічного складу сталей, до механічних властивостей, до якості поверхні $і$ до геометричних розмірів, форми $і$ масі труб, до методів неруйнівного контролю та випробувань, до методів приймання та контролю, маркування, упаковки, транспортування і зберігання, а також до технології виробництва труб. 3 урахуванням викладеного виробники трубної продукиії будуть змушені здійснити рішучі заходи щзодо заміни вже застарілих трубопрокатних агрегатів або їх докорінної реконструкиії з урахуванням економічної доиільності.

Ключові слова: гарячедеформовані труби, показники якості, трубопрокатний агрегат, хімічний склад, механічні властивості, неруйнівний контроль.

Purpose. With the exploration of new hydrocarbon deposits, the difference in occurrence of pay formations, maintaining the flow rate of existing wells, science faces with the constant need to solve the problems of creating new well casing programs, threaded pipe joints and sleeve pipes, increasing the strength characteristics of metal, tightening control of technological parameters, etc.

Methodology. The analysis of the tightening of pipe quality requirements revealed that changes in these requirements, taking into account existing assessment methods, affected absolutely all components of the quality of pipe products, starting from the requirements for raw materials and ending with the requirements for the presentation of the product and the technology of its production. Wherein there were compared the requirements of existing domestic, foreign and international pipe standards and specifications of the world's leading pipe consuming companies.

Scientific novelty. The results of the analysis of modern quality requirements and technology for the production of hot-finished pipes for exploration, production and transportation of oil and gas were generated. There were identified the development and improvement trends of oil pipe production technologies.

Results, practical relevance. Based on the specifications of the world's leading oil and gas companies (SHELL, SHEVRON, EXONN MOBIL, ADCO, SAUDI ARAMCO, LUKOIL, GAZPROM, ROSNEFT, etc.) there were analyzed current trends in the development of requirements for pipe products quality indicators, for hot-finished oil pipes in particular. There are presented the requirements for the steel and pipe billet production method, for the chemical composition of steels and mechanical characteristics along with the requirements for quality of surface and metal, geometric dimensions, shape and mass of pipes, nondestructive control and testing methods, methods of acceptance and control, labeling, packaging, transportation, storage and also for pipe production technology.

Key words: hot-finished pipes, quality indicators, pipe-rolling plant, chemical composition, mechanical characteristics, nondestructive control.

Рукопись поступила 24.07.2019 